\title{
Cogumelo "shiitake" (Lentinula edodes) reduz o crescimento de fitopatógenos e a severidade de manchas foliares em sorgo
}

\author{
Everaldo Piccinin ${ }^{1}$, Robson Marcelo Di Piero ${ }^{2} \&$ Sérgio Florentino Pascholati ${ }^{1}$
}

\begin{abstract}
${ }^{(1)}$ Universidade de São Paulo, Escola Superior de Agricultura "Luiz de Queiroz”, Departamento de Entomologia, Fitopatologia e Zoologia Agrícola, CEP 13418-900 Piracicaba, SP. ${ }^{(2)}$ Universidade Federal de Santa Catarina, Centro de Ciências Agrárias, Departamento de Fitotecnia, CEP 88040-900 Florianópolis, SC.
\end{abstract}

Autor para correspondência: Sérgio Florentino Pascholati - (sfpascho@esalq.usp.br)

Data de chegada: 14/01/2008. Aceito para publicação em: 27/07/2009.

\section{RESUMO}

Piccinin, E.; Di Piero, R.M.; Pascholati, S.F. Cogumelo "shiitake" (Lentinula edodes) reduz o crescimento de fitopatógenos e a severidade de manchas foliares em sorgo. Summa Phytopathologica, v.36, n.1, p.68-72, 2010.

Lentinula edodes (cogumelo "shiitake") é um fungo basidiomiceto que apresenta propriedades nutricionais, medicinais e antibióticas. Compostos de interesse para o homem têm sido isolados do basidiocarpo e dos filtrados de cultura obtidos a partir do crescimento micelial. O presente trabalho teve como objetivos avaliar o efeito de diferentes preparações de L. edodes sobre patógenos da cultura do sorgo, Exserohilum turcicum e Colletotrichum sublineolum, bem como a proteção das plantas de sorgo contra estes patógenos. Em testes com placas de Petri e lâminas de vidro para microscopia, extratos aquosos obtidos do basidiocarpo inteiro e de suas partes individualizadas, píleo e estipe, reduziram a taxa de crescimento micelial e inibiram a germinação de esporos dos fungos, enquanto a atividade antifúngica do filtrado de crescimento micelial foi menos pronunciada. Em mesocótilos de sorgo, as diferentes preparações do "shiitake" não provocaram o acúmulo de fitoalexinas. O extrato aquoso do basidiocarpo e o composto lentinana reduziram parcialmente a severidade das doenças provocadas por E. turcicum na cv. Brandes e por C. sublineolum na cv. Tx-398-B, quando pulverizados 48 horas antes da inoculação das plantas, sob condições de casa de vegetação. Portanto, L. edodes apresenta potencial como agente de controle biológico ou como um modelo para a síntese de substâncias fungicidas.

Palavras-chave adicionais: Lentinula edodes, antibiose, Exserohilum turcicum, Colletotrichum sublineolum, Sorghum bicolor.

\section{ABSTRACT}

Piccinin, E.; Di Piero, R.M.; Pascholati, S.F. "shiitake" (Lentinula edodes) mushroom reduces growth of plant pathogens and leaf spot severity in sorghum. Summa Phytopathologica, v.36, n.1, p.68-72, 2010.

Lentinula edodes ("shiitake" mushroom) is a fungus that presents nutritional, medicinal and antibiotic properties. Valuable compounds have been isolated from the fruiting bodies and from mycelium growth filtrates. The present work had as objectives the evaluation of the effect of L. edodes preparations on two sorghum pathogens, Exserohilum turcicum and Colletotrichum sublineolum, as well as the protection of sorghum plants against those fungi. When in vitro studies were carried out, aqueous extracts from the whole fruiting bodies and also from fruiting body parts, cap and stem, reduced the mycelium growth and the spore germination of the plant pathogens, while the antifungal activity of $L$. edodes's mycelium growth filtrate was less pronounced. The shiitake preparations did not induce phytoalexin accumulation in sorghum mesocotyls. Aqueous extracts from fruiting bodies and lentinan partially reduced disease severity caused by E. turcicum in the cv. Brandes and by C. sublineolum in the cv. Tx-398-B, when applied 48 hours before plant inoculation. Therefore, L. edodes exhibits potential as a biological control agent or as a model for the synthesis of fungicidal compounds.

Keywords: Lentinula edodes, antibiosis, Exserohilum turcicum, Colletotrichum sublineolum, Sorghum bicolor.

Lentinula edodes (Berk.) Pegler, conhecido como cogumelo "shiitake", é a segunda mais importante espécie de cogumelo comestível cultivada no mundo, ficando atrás apenas do "champignon" de Paris (Agaricus bisporus). A produção mundial é crescente, sendo a China o principal país produtor (1). No Brasil, a produção de "shiitake" está se expandindo, principalmente nas regiões sul e sudeste, dadas as condições climáticas favoráveis (9).

O "shiitake" pode ser cultivado em troncos de árvores como o eucalipto, carvalho, mangueira e abacateiro, ou em substratos preparados pelo homem, sob condições controladas, e tem atraído a atenção de pesquisadores por apresentar qualidades nutricionais, medicinais e terapêuticas comprovadas cientificamente (4).
A atividade antibiótica de L. edodes foi demonstrada em experimentos envolvendo fungos, vírus e bactérias, a partir de compostos produzidos durante o crescimento micelial em laboratório $(6,7,9,15)$, assim como a partir de substâncias encontradas no basidiocarpo $(5,8,12)$.

$\mathrm{Na}$ área médica, resultados positivos foram verificados com a utilização de L. edodes no combate a patógenos humanos, e também na ativação do sistema imunológico e na melhora de problemas de saúde como o colesterol, a asma e a úlcera. Entre as substâncias caracterizadas, destaca-se a lentinana, uma â-glucana isolada do basidiocarpo por extração aquosa. A lentinana possui a capacidade de recuperar ou aumentar a resposta das células hospedeiras a substâncias 
biologicamente ativas, por estimular a maturação, diferenciação ou proliferação de células envolvidas nos mecanismos de defesa, aumentando a resistência do hospedeiro contra vários tipos de câncer e doenças infecciosas (2). Além da ativação do sistema imune em animais, L. edodes pode ativar mecanismos de defesa em vegetais. Em plantas de pepino, extratos aquosos do basidiocarpo provocaram um aumento foliar na atividade de enzimas relacionadas à defesa, o que pode ter contribuído para a proteção parcial observada em tais plantas contra Colletotrichum lagenarium (3).

Atualmente, uma das principais preocupações do homem está relacionada à preservação dos recursos naturais, bem como à qualidade dos alimentos consumidos. Na agricultura, o uso de produtos fitossanitários menos tóxicos e com baixo impacto ambiental tem sido uma das exigências do mercado consumidor e dos agricultores. Nesse sentido, esse trabalho teve como objetivo avaliar o efeito antibiótico de várias preparações obtidas a partir do cogumelo L. edodes sobre dois fungos fitopatogênicos, Exserohilum turcicum (Pass.) e Colletotrichum sublineolum Ces (Wils), causadores de doenças foliares em plantas de sorgo (Sorghum bicolor Moench). Além disso, as preparações do cogumelo foram aplicadas em duas cultivares de sorgo para se avaliar o efeito protetor contra os fitopatógenos, buscando medidas alternativas aos fungicidas convencionais para o controle de doenças em plantas.

\section{MATERIAL E MÉTODOS}

\section{Lentinula edodes e fitopatógenos}

Em todos os testes, utilizou-se o isolado de L. edodes ("shiitake") denominado Piracicaba, o qual se encontra depositado na micoteca do Instituto de Botânica, em São Paulo, com o número de registro CCB 654. O crescimento micelial de L. edodes foi realizado em condições de laboratório, cultivando-se o fungo em BDA, no escuro, a $22 \pm 2{ }^{\circ} \mathrm{C}$. Os basidiocarpos foram obtidos após o cultivo do fungo em toras de Eucalyptus grandis, em local sombreado. O isolamento de L. edodes, o preparo de inóculo, a inoculação das toras e a colheita dos basidiocarpos foram conduzidos seguindo-se a metodologia de Pascholati et al. (16).

Para a obtenção dos extratos aquosos (EA), os basidiocarpos ou suas partes constituintes individualizadas (píleo e estipe), desidratados em pó, foram misturados com água destilada (14 mL para cada grama), e após $4 \mathrm{~h}$ de incubação a $4{ }^{\circ} \mathrm{C}$, a suspensão foi filtrada em filtro

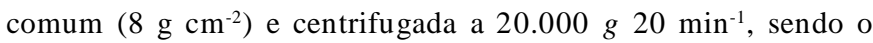
sobrenadante filtrado em membrana tipo Millipore (diâmetro do poro $=0,2 \mu \mathrm{m}$ ), sob condições assépticas. Os extratos aquosos brutos foram armazenados em geladeira a $4{ }^{\circ} \mathrm{C}$ e utilizados, após diluições, nos testes in vitro e in vivo (18).

Outro tipo de preparação utilizada foi o filtrado de crescimento micelial (FCM). Para tal, 12 discos $(0,5 \mathrm{~cm}$ de diâmetro) retirados de BDA contendo crescimento vegetativo de L. edodes foram repicados para seis erlenmeyers contendo $300 \mathrm{~mL}$ de meio líquido BD (batatadextrose) cada um. Após 160 dias de cultivo, a $25 \pm 2{ }^{\circ} \mathrm{C}$, sob agitação, o conteúdo dos erlenmeyers foi filtrado e armazenado de forma semelhante ao descrito anteriormente. A lentinana, uma â-glucana presente na parede celular do cogumelo, foi cedida pela Ajinomoto Indústria e Comércio Ltda.

Colletotrichum sublineolum e Exserohilum turcicum foram isolados a partir de folhas de sorgo das cultivares Tx-398-B e Brandes, respectivamente. Culturas puras dos patógenos foram mantidas em BDA, a $26 \pm 2{ }^{\circ} \mathrm{C}$, visando estimular o crescimento micelial. Para induzir a esporulação, C. sublineolum foi cultivado em meio de aveia, a $21 \pm 2{ }^{\circ} \mathrm{C}$, sob luz negra $(\ddot{\mathrm{e}}=320 \mathrm{~nm})$ durante 20 dias, enquanto $E$. turcicum foi mantido em BDA, a $26 \pm 2{ }^{\circ} \mathrm{C}$, no escuro, por 30 dias.

\section{Testes in vitro}

Para testar o efeito de L. edodes sobre o crescimento micelial dos patógenos, cada uma das preparações do cogumelo (extrato aquoso de basidiocarpo, EAB; extrato aquoso do píleo, EAP; extrato aquoso da estipe, EAE; e o filtrado do crescimento micelial, FCM) foi incorporada separadamente em $150 \mathrm{~mL}$ de BDA a $45{ }^{\circ} \mathrm{C}$, nas proporções de 0 ; 0,$01 ; 0,1 ; 1$ e $2 \%$ (v/v) e vertida em placas de Petri. Três dias depois, cada placa recebeu um disco de $0,5 \mathrm{~cm}$ de diâmetro contendo micélio de um dos patógenos, na parte central. Foram realizadas seis repetições para cada concentração testada, em delineamento inteiramente casualizado. As placas onde se repicou $C$. sublineolum foram mantidas a $22 \pm 1{ }^{\circ} \mathrm{C}$, sob luz fluorescente, enquanto as placas contendo $E$. turcicum foram mantidas a $27 \pm 2{ }^{\circ} \mathrm{C}$, sob condições de escuro. $\mathrm{O}$ crescimento diametral das colônias fúngicas foi avaliado quando o micélio presente em um dos tratamentos alcançou o diâmetro máximo da placa de Petri $(9 \mathrm{~cm})$.

A influência das preparações de L. edodes sobre a germinação dos conídios dos patógenos foi determinada através do uso de lâminas de vidro para microscopia recobertas com uma camada de poliestireno (10). Aunidade experimental foi representada por uma lâmina contendo duas gotas, sendo cada gota composta por $40 \mu \mathrm{L}$ de suspensão de esporos do patógeno $+40 \mu \mathrm{L}$ de uma preparação do cogumelo, de tal forma que a concentração final dos patógenos na gota fosse $10^{4}$ esporos $\mathrm{mL}^{-1}$ e a concentração final das preparações do cogumelo fosse $2 \mathrm{ou}$ $5 \%(\mathrm{v} / \mathrm{v})$. Neste ensaio, foram testadas as preparações EAB, EAP, EAE, FCM e lentinana. O controle geral consistiu de água destilada, enquanto o meio líquido batata-dextrose (BD) foi utilizado como um segundo controle, específico para o FCM. Foram realizadas três repetições para cada tratamento, em um delineamento inteiramente casualizado. As lâminas contendo $C$. sublineolum foram incubadas a $21 \pm 2{ }^{\circ} \mathrm{C}$ e sob luz negra, enquanto as contendo E. turcicum foram mantidas a $27 \pm 2{ }^{\circ} \mathrm{C}$, no escuro, realizando-se câmara úmida para todas as lâminas. A porcentagem de germinação de conídios foi determinada 24 h após o início dos experimentos, através do emprego de azul de algodão com lactofenol e observação em microscópio ótico. Foram avaliados 100 esporos em cada gota.

\section{Bioensaio com mesocótilos de sorgo e testes de proteção de plantas em casa de vegetação}

Para analisar o efeito das preparações de L. edodes no acúmulo de fitoalexinas em mesocótilos de sorgo, sementes de sorgo da cultivar Brandes foram embebidas em água por $4 \mathrm{~h}$, sob aeração e a temperatura ambiente, e dispostas entre camadas de papel de filtro umedecidas, no escuro a $28{ }^{\circ} \mathrm{C}$. Após 5 dias, as plântulas foram expostas a duas horas de luz para a paralisação da elongação dos mesocótilos. Estes foram coletados e colocados no interior de tubos de ensaio contendo $3 \mathrm{~mL}$ das diferentes preparações de L. edodes (EAB, EAP, EAE, FCM e lentinana). O controle geral consistiu de água destilada e o meio líquido BD foi utilizado como um segundo controle, específico para o FCM. Foram feitas cinco repetições por tratamento, onde cada unidade experimental foi representada por um tubo de ensaio contendo cinco mesocótilos. Os tubos de ensaio foram vedados com plástico Magipack $^{\circledR}$ e incubados sob luz fluorescente constante, a $25 \pm 2{ }^{\circ} \mathrm{C}$, durante $60 \mathrm{~h}$. Após esse período, eliminou-se $0,5 \mathrm{~cm}$ da base dos mesocótilos, e os 2,0 cm acima foram pesados e colocados em 1,4 mL 
de metanol $80 \%$ acidificado com $0,1 \%$ (v/v) $\mathrm{HCl}$, a $4{ }^{\circ} \mathrm{C}$ durante $96 \mathrm{~h}$. Posteriormente, as frações metanólicas das amostras foram separadas dos tecidos e a absorbância determinada em espectrofotômetro a 480 $\mathrm{nm}$ (13). A atividade elicitora dos preparados foi calculada em termos de Absorbância a $480 \mathrm{~nm} \mathrm{~g}^{-1}$ tecido fresco.

Plantas de sorgo foram cultivadas em vasos de alumínio de $2 \mathrm{~L}$ preenchidos com terra e esterco curtido, na proporção de 3:1, mantidos em casa de vegetação. Para verificar a proteção de sorgo contra $C$. sublineolum, plantas da cultivar Tx398-B, apresentando quatro folhas expandidas, foram aspergidas separadamente com preparações de $L$. edodes (EAB a $2 \% \mathrm{v} / \mathrm{v}$ e lentinana a $2 \% \mathrm{~m} / \mathrm{v}$ ) ou com água destilada, utilizando-se um volume médio de $5,5 \mathrm{~mL}$ por planta. Os tratamentos foram efetuados em todas as folhas das plantas. Quarenta e oito horas após os tratamentos, as plantas foram inoculadas com $C$. sublineolum ( $5 \times 10^{4}$ conídios $\left.\mathrm{mL}^{-1}\right)$ em todas as folhas, permanecendo sob condições de câmara úmida e luz constante durante $24 \mathrm{~h}$. Após este período, as plantas retornaram para a casa de vegetação. Foram feitas cinco repetições por tratamento e cada repetição consistiu de um vaso contendo três plantas. O delineamento foi inteiramente casualizado. A avaliação foi realizada estimando-se a severidade da doença na $5^{\text {a }}$ folha, aos 30 dias após a inoculação, com base em escala diagramática (17).

$\mathrm{Na}$ verificação do efeito protetor de L. edodes contra E. turcicum, o procedimento geral foi o mesmo descrito no parágrafo anterior. No entanto, utilizou-se a cultivar de sorgo Brandes, e as plantas foram inoculadas com uma suspensão de $5 \times 10^{5}$ esporos $\mathrm{mL}^{-1}$ de E. turcicum. As 24 h de câmara úmida foram realizadas sob condições de escuro, e posteriormente, as plantas foram mantidas em ambiente controlado $\left(25 \pm 2{ }^{\circ} \mathrm{C}\right.$ e fotoperíodo de $16 \mathrm{~h}$ ) até o final do experimento. A avaliação foi efetuada 45 dias após a inoculação, estimando-se a severidade da doença na $5^{\text {a }}$ folha de cada planta.

\section{RESULTADOS E DISCUSSÃO}

Os extratos aquosos obtidos do basidiocarpo de L. edodes como um todo (EAB) ou de suas partes constituintes, píleo e estipe, (EAP e EAE) reduziram o crescimento micelial de $E$. turcicum e de $C$. sublineolum, a partir da concentração de $1 \%$ (v/v) (Figura 1). À semelhança do observado por Takazawa et al. (20), o efeito do cogumelo foi apenas fungistático, já que houve desenvolvimento dos fitopatógenos quando os discos contendo micélio dos mesmos foram retirados dos tratamentos e colocados em BDA onde não haviam sido incorporadas as preparações do cogumelo.

O filtrado de crescimento micelial (FCM) do cogumelo inibiu o crescimento de E. turcicum em intensidade semelhante à das preparações de basidiocarpo (Figura 1A). No entanto, não teve efeito sobre C. sublineolum (Figura 1B), revelando que os patógenos estudados apresentam sensibilidade diferencial com relação a compostos presentes no FCM.

Na mesma linha de pesquisa, Maki (11) e Sasaki et al. (19) demonstraram a produção de antibióticos antifúngicos por parte de $L$. edodes. Extratos obtidos a partir do crescimento micelial de L. edodes inibiram o desenvolvimento in vitro dos fungos filamentosos Helminthosporium sp., Fusarium solani e Phomopsis sojae, agentes causais da helmintosporiose do trigo, da síndrome da morte súbita em soja, e da seca das hastes e das vagens em soja, respectivamente (19). Por sua vez, Maki (11) reportou a liberação de substâncias inibitórias a Candida albicans para o substrato de crescimento de L. edodes. A atividade antibiótica do cogumelo desidratado e transformado em pó sobre a levedura C. albicans não foi reduzida comparado ao cogumelo fresco (14).

Além de inibir o desenvolvimento micelial, as preparações obtidas a partir do basidiocarpo (EAB, EAP e EAE) reduziram significativamente a germinação de esporos de E. turcicum e de $C$. sublineolum (Figura 2), quando utilizadas a $2 \%(\mathrm{v} / \mathrm{v})$. A lentinana também apresentou efeito inibitório sobre a germinação de esporos dos patógenos (Figura 2). No caso do FCM, o efeito inibidor foi menos pronunciado e só ocorreu no teste envolvendo E. turcicum e, ainda assim, quando se utilizou a concentração mais elevada, 5\% v/v (Figura 2A), enquanto que no teste com C. sublineolum, o FCM não diferiu estatisticamente do seu controle, o meio líquido BD (Figura 2B).

De maneira geral, a autoclavagem dos extratos a $121^{\circ} \mathrm{C} / 20 \mathrm{~min}$ pouco alterou o desempenho das preparações nos testes in vitro (dados não mostrados), revelando que as substâncias antifúngicas produzidas por L. edodes apresentam natureza termo-resistente. Já o extrato aquoso de basidiocarpo autoclavado (EABA), obtido a partir da autoclavagem do basidiocarpo antes da realização da extração aquosa, inibiu o crescimento micelial dos patógenos em maior intensidade que o EAB (dados não mostrados), mas por outro lado, estimulou a germinação de esporos de C. sublineolum (Figura 2B). É provável que a autoclavagem do basidiocarpo tenha aumentado a solubilidade em
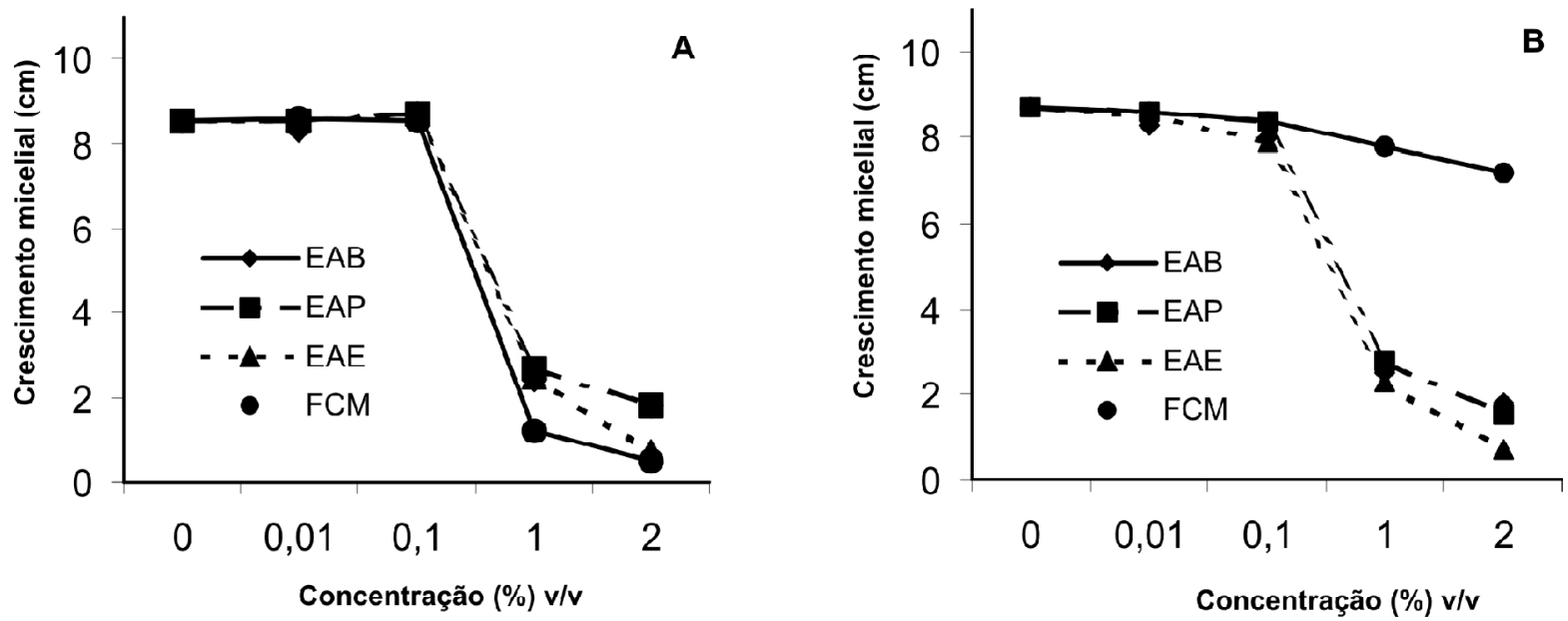

Figura 1. Efeito de preparações de Lentinula edodes sobre o crescimento micelial de Exserohilum turcicum (A) e de Colletotrichum sublineolum (B). $\mathrm{EAB}=$ extrato aquoso do basidiocarpo; EAP $=$ extrato aquoso do píleo; $\mathrm{EAE}=$ extrato aquoso da estipe; FCM $=$ filtrado do crescimento micelial. 

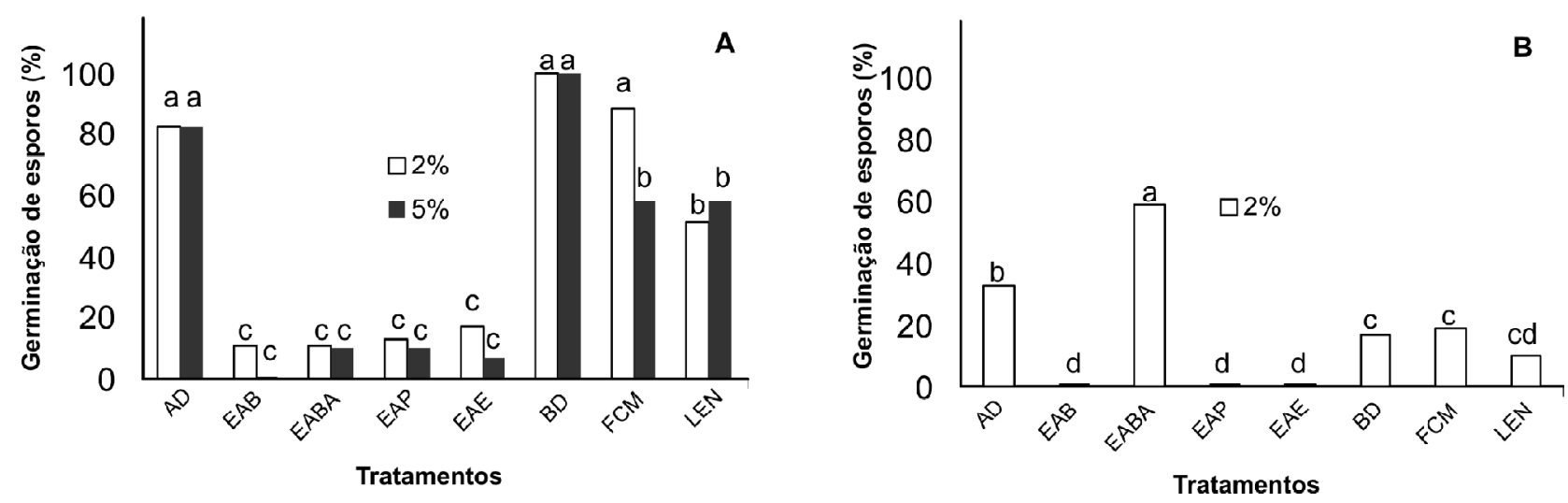

Figura 2. Efeito de preparações de Lentinula edodes sobre a germinação de esporos de Exserohilum turcicum (A) e de Colletotrichum sublineolum (B). $\mathrm{AD}=$ água destilada; $\mathrm{EAB}=$ extrato aquoso do basidiocarpo; $\mathrm{EABA}=\mathrm{EAB}$ autoclavado; $\mathrm{EAP}=$ extrato aquoso do píleo; EAE $=$ extrato aquoso da estipe; $\mathrm{BD}=$ batata-dextrose (meio de cultura líquido); FCM = filtrado do crescimento micelial; LEN = lentinana. As barras representam a médias. Médias seguidas por letras iguais não diferem significativamente a $1 \%$ pelo teste de Tukey.

água de compostos atuando sobre o micélio de E. turcicum e de $C$. sublineolum, e também de nutrientes que devem ser os responsáveis pelo estímulo à germinação de esporos.

As diferentes preparações do cogumelo "shiitake" não desencadearam um acúmulo significativo de fitoalexinas nos mesocótilos de sorgo, um dos importantes mecanismos de defesa vegetal nessa espécie (Tabela 1). O maior efeito foi o do meio líquido $\mathrm{BD}$, meio utilizado como um dos controles para o FCM.

Com relação à proteção de sorgo, tanto o extrato aquoso do basidiocarpo a $2 \%(\mathrm{v} / \mathrm{v})$ como a lentinana $\left(2 \mathrm{~g} 100 \mathrm{~mL}^{-1}\right)$ reduziram significativamente as doenças causadas por E. turcicum na cv. Brandes e por C. sublineolum na cv. Tx 398-B, quando aplicados $48 \mathrm{~h}$ antes da inoculação (Tabela 2). Esse é o primeiro relato da proteção de duas cultivares de sorgo contra patógenos pela aplicação foliar de metabólitos produzidos por um cogumelo.

A inibição no crescimento micelial e na germinação de esporos dos patógenos testados, bem como a baixa capacidade de elicitar o acúmulo de fitoalexinas, apontam a antibiose como um dos mecanismos de ação envolvidos no controle das doenças em plantas de sorgo pelas preparações de L. edodes.

Tabela 1. Atividade elicitora do acúmulo de fitoalexinas em mesocótilos de sorgo por preparações de Lentinula edodes, utilizadas a $2 \%$ (v/v).

\begin{tabular}{|c|c|}
\hline Tratamento & $\begin{array}{l}\text { Acúmulo de fitoalexinas } \\
\text { (Abs } 480 \mathrm{~nm} \mathrm{~g}^{-1} \text { tecido fresco) }\end{array}$ \\
\hline Água destilada & $0,7 \quad b^{1}$ \\
\hline Extrato aquoso do basidiocarpo (EAB) & $1,1 \mathrm{ab}$ \\
\hline EAB autoclavado & $0,5 \quad b$ \\
\hline Extrato aquoso do píleo & $1,4 \mathrm{ab}$ \\
\hline Extrato aquoso da estipe & $1,0 \mathrm{ab}$ \\
\hline Batata-dextrose & $2,7 \mathrm{a}$ \\
\hline Filtrado do crescimento micelial & $1,4 \mathrm{ab}$ \\
\hline Lentinana $^{2}$ & $0,6 \mathrm{~b}$ \\
\hline Colletotrichum sublineolum ${ }^{3}$ & 35,6 \\
\hline \multicolumn{2}{|c|}{$\begin{array}{l}{ }^{(1)} \text { Médias seguidas por letras iguais não diferem significativamente a } 1 \% \text { pelo teste de } \\
\text { Tukey. } \\
\text { (2) Lentinana foi utilizada na proporção de } 2 \mathrm{~g} \text { para } 100 \mathrm{~mL} \text { de água destilada. } \\
{ }^{(3)} \text { Uma suspensão de esporos de Colletotrichum sublineolum }\left(10^{5} \text { esporos } / \mathrm{mL}\right) \text { foi utilizada } \\
\text { como controle positivo. }\end{array}$} \\
\hline
\end{tabular}

Tabela 2. Efeito de preparações de Lentinula edodes sobre a severidade de doenças foliares causadas por Exserohilum turcicum e Colletotrichum sublineolum em plantas de sorgo das cultivares Brandes e Tx 398-B, respectivamente. Tratamentos realizados $48 \mathrm{~h}$ antes das inoculações.

\begin{tabular}{llr}
\hline & \multicolumn{3}{c}{ Severidade $(\%)$} \\
\cline { 2 - 3 } Tratamentos & $\begin{array}{l}\text { cv. Brandes } \\
\text { x E. turcicum }\end{array}$ & $\begin{array}{l}\text { cv. Tx 398-B } \\
\text { x C. sublineolum }\end{array}$ \\
\hline Água & $27,8 \mathrm{a}^{(1)}$ & $25,4 \mathrm{a}$ \\
Extrato aquoso basidiocarpo $^{(2)}$ & $18,2 \mathrm{~b}$ & $7,0 \mathrm{~b}$ \\
Lentinana $^{(3)}$ & $20,8 \mathrm{~b}$ & $10,6 \mathrm{~b}$ \\
\hline
\end{tabular}

${ }^{(1)}$ Médias seguidas por letras iguais, na coluna, não diferem significativamente a $1 \%$ pelo teste de Tukey. ${ }^{(2)}$ Utilizado na proporção de $2 \%$ (v/v). ${ }^{(3)}$ Utilizada na proporção de $2 \mathrm{~g}$ para $100 \mathrm{~mL}$ de água destilada.

Substâncias antibióticas produzidas por microrganismos são utilizadas para o desenvolvimento de fungicidas de alta eficiência e de amplo espectro de atuação. $\mathrm{O}$ caso de maior sucesso na agricultura ocorreu com a descoberta das estrobilurinas produzidas pelo cogumelo Strobilurus tenacellus, as quais originaram, após algumas modificações visando melhorar a estabilidade das moléculas, os fungicidas azoxystrobin e cresoxim-metil, empregados atualmente na agricultura mundial (21).

Por sua vez, L. edodes produz substâncias que reduzem o desenvolvimento de $E$. turcium e de $C$. sublineolum, assim como a severidade de manchas foliares em sorgo provocadas por esses patógenos. Os resultados do presente trabalho evidenciaram o potencial do cogumelo "shiitake" para o controle de fitopatógenos e encorajam a realização de novas pesquisas buscando compostos de baixo impacto ambiental que possam ser empregados no manejo integrado de doenças de plantas.

\section{REFERÊNCIAS BIBLIOGRÁFICAS}

1. Chang, S.T.; Kwan, H.S.; Kang, Y.N. Collection, characterization and utilization of germ plasm of Lentinula edodes. Canadian Journal of Botany, Ottawa, v.73, n.1, p.955-961, 1995.

2. Chihara, G. Medical aspects of lentinan isolated from Lentinus edodes. In: Chang, S.T.; Buswell, J.A.; Chiu, S.W. Mushroom biology and mushroom products. Hong Kong: The Chinese University Press, 1993. p.261-266.

3. Di Piero, R.M.; Pascholati, S.F. Indução de resistência em plantas 
de pepino contra Colletotrichum lagenarium pela aplicação de extratos de basidiocarpos de Lentinula edodes e de Agaricus blazei. Summa Phytopathologica, Botucatu, v.30, n.2, p.243-250, 2004

4. Eira, A.F.; Kaneno, R.; Rodrigues Filho, E.; Barbisan, L.F.; Pascholati, S.F.; Di Piero, R.M.; Salvadori, D.M.F.; Lima, P.L.A.; Ribeiro, L.R. Farming technology, biochemistry characterization, and protective effects of culinary-medicinal mushrooms Agaricus brasiliensis and Lentinus edodes: five years of research in Brazil. International Journal of Medicinal Mushrooms, Israel, v.7, n.1/2, p.281-300, 2005 .

5. Fiori-Tutida,A.C.G.; Schwan-Estrada, K.R.F.; Stangarlin, J.R.; Pascholati, S.F. Extratos de Lentinula edodes e Agaricus blazei sobre Bipolaris sorokiniana e Puccinia recondita f.sp. tritici, in vitro. Summa Phytopathologica, Botucatu, v.33, n.3, p.287289, 2007.

6. Hassegawa, R.H.; Kasuva, M.C.M.; Vanetti, M.C.D. Growth and antibacterial activity of Lentinula edodes in liquid media supplemented with agricultural wastes. Electronic Journal of Biotechnology, Valparaíso, v.8, n.2, p.212-217, 2005.

7. Hatvani, N. Antibacterial effect of the culture fluid of Lentinus edodes mycelium grown in submerged liquid culture. International Journal of Antimicrobial Agents, Amsterdam, v.17, n.1, p.71-74, 2001

8. Hirasawa, M.; Shouji, N.; Neta, T.; Fukushima, K.; Takada, K. Three kinds of antibacterial substances from Lentinus edodes. International Journal of Antimicrobial Agents, Amsterdam, v.11, n.2, p.151-157, 1999.

9. Ishikawa, N.Z.; Kasuya, M.C.M.; Vanetti, M.C.D. Antibacterial activity of Lentinula edodes grown in liquid medium. Brazilian Journal of Microbiology, São Paulo, v.32, n.3, p.206-210, 2001.

10. Leite, B.; Nicholson, R.L. Mycosporine-alanine: a self-inhibitor of germination from the conidial mucilage of Colletotrichum graminicola. Experimental Mycology, New York, v.16, n.1, p.7686, 1992.

11. Maki, C.S. Respostas fungistáticas de Lentinula edodes sobre Candida albicans e análise da variabilidade intraespecífica. 1999. 109p. Dissertação (Mestrado em Genética e Biologia Molecular) - Universidade Estadual de Londrina, Londrina.

12. Ngai, P.H.K.; Ng, T.B. Lentin, a novel and potent antifungal protein from shitake mushroom with inhibitory effects on acti- vity of human immunodeficiency virus-1 reverse transcriptase and proliferation of leukemia cells. Life Sciences, Stockholm, v.73, n.26, p.3363-3374, 2003.

13. Nicholson, R.L.; Kollipara, S.S.; Vicent, J.R.; Lyons, P.C.; Cadena-Gomez, G. Phytoalexin synthesis by the sorghum mesocotyl in response to infection by pathogenic and nonpathogenic fungi. Proceedings of the National Academy of Science of the U.S.A., Washington, v.84, n.16, p.5520-5524, 1987.

14. Paccola, E.A.S.; Maki, C.S.; Nobrega, G.M.A.; Paccola-Meirelles, L.D. Antagonistic effect of edible mushroom extract on Candida albicans growth. Brazilian Journal of Microbiology, São Paulo, v.32, n.3, p.176-178, 2001.

15. Pacumbaba, R.P; Beyl, C.A.; Pacumbaba, R.O. Shiitake mycelial leachate suppresses growth of some bacterial species and symptoms of bacterial wilt of tomato and lima bean in vitro. Plant Disease, St Paul, v.83, n.1, p.20-23, 1999.

16. Pascholati, S.F.; Stangarlin, J.R.; Piccinin, E. Cogumelos: cultivo e comercialização (shiitake e cogumelo do sol). Cuiabá, SEBRAE, 1998. v.1, 78p.

17. Piccinin, E. Uso de Saccharomyces cerevisiae na proteção de plantas de sorgo (Sorghum bicolor), maracujá azedo amarelo (Passiflora edulis) e eucalipto (Eucalyptus spp.) contra fitopatógenos fúngicos e bacterianos. 1995. 107 p. Dissertação (Mestrado em Fitopatologia). Escola Superior de Agricultura "Luiz de Queiroz", Universidade de São Paulo, Piracicaba.

18. Piccinin, E. Potencial de preparações do cogumelo comestível shiitake (Lentinula edodes) no controle de fitopatógenos fúngicos, bacterianos e virais em sorgo, maracujá e fumo. 2000. 162 p. Tese (Doutorado em Fitopatologia). Escola Superior de Agricultura "Luiz de Queiroz", Universidade de São Paulo, Piracicaba.

19. Sasaki, S.H.; Linhares, R.E.C.; Nozawa, C.M. Linhagens de Lentinula edodes inibem fungos fitopatogênicos e o vírus da estomatite vesicular, sorotipo Alagoas. Brazilian Journal of Microbiology, São Paulo, v.32, n.1, p.52-55, 2001.

20. Takazawa, H.; Tajima, F.; Miyashita, C. An antifungal compound from shiitake (Lentinula edodes). Yakugaku Zasshi, Japão, v. 102, n.5, p.489-491, 1982.

21. Ypema, H.L.; Gold, R.E. Kresoxim-methyl: modification of a naturally occurring compound to produce a new fungicide. Plant Disease, St Paul, v.83, n.1, p.4-19, 1999. 